\title{
Processos educativos pelas veredas do esperançar
}

\author{
Educative processes through the ways of hope
}

Procesos educativos a través de los caminos de la esperanza

\author{
DJALMA RIBEIRo JUNIOR ${ }^{1}$; MARIA WALDENEZ DE OLIVEIRA ${ }^{2}$ \\ UNIVERSIDADE FEDERAL DE SÃo CARLOS, UFSCAR, SÃo CARLOS-SP, BRASIL
}

\begin{abstract}
RESUMO
O ensaio busca compreender aspectos que contribuem para a construção do esperançar como ação que mobiliza e que une pessoas em torno de um projeto de mundo em comum. Para tecer esta compreensão, parte-se da leitura crítica da tese de doutorado intitulada "Processos educativos vivenciados em experiências de comunicação popular na Mostra Audiovisual de Cambuquira-MG (MOSCA)", defendida em 2016, junto ao Programa de PósGraduação em Educação da UFSCar, por Djalma Ribeiro Junior e sob orientação de Maria Waldenez de Oliveira. Dessa maneira, busca-se evidenciar as falas dos sujeitos da pesquisa, a concepção de ciência e as dimensões metodológicas que orientaram a elaboração da tese, no intuito de apontar que a construção do esperançar pode se dar por meio de algumas dimensões, das quais é dado destaque para o diálogo, o convívio dialógico e a comunhão de projetos de mundo que encaminham a construção de conhecimentos com compromisso social.
\end{abstract}

Palavras-chave: Processos Educativos. Esperançar. Metodologia de Pesquisa. Diálogo.

\begin{abstract}
The essay seeks to understand aspects that contribute to the construction of hope as an action that mobilizes and unites people around a common world project. To weave this understanding, we start with a critical reading of the doctoral thesis entitled "Educative processes experienced in popular communication experiences at the Mostra Audiovisual de Cambuquira-MG (MOSCA)", defended in 2016, together with the Postgraduate Program in Education from UFSCar, by Djalma Ribeiro Junior and under the guidance of Maria Waldenez de Oliveira. In this way, we seek to highlight the speeches of the research subjects, the conception of science and the methodological dimensions that guided the preparation of the thesis, in order to point out that the construction of hope can occur through some dimensions, of which it is emphasis was given to dialogue, dialogical interaction and the communion of world projects that lead to the construction of knowledge with social commitment.
\end{abstract}

Keywords: Educative Processes. Hope. Research Methodology. Dialogue.

\section{RESUMEN}

El ensayo busca comprender aspectos que contribuyan a la construcción de la esperanza como acción que moviliza y une a las personas en torno a un proyecto de mundo común. Para tejer este entendimiento partimos de una lectura crítica de la tesis doctoral titulada "Procesos educativos vividos en experiencias de comunicación popular en la Mostra Audiovisual de Cambuquira-MG (MOSCA)", defendida en 2016, junto con el Programa de Posgrado en Educación. de la UFSCar, a cargo de Djalma Ribeiro Junior y bajo la supervisión de Maria Waldenez de Oliveira. De esta manera, buscamos resaltar los discursos de los sujetos de investigación, el concepto de ciencia y las dimensiones metodológicas que guiaron la elaboración de la tesis, con el fin de señalar que la construcción de la esperanza puede darse a través de algunas dimensiones, de las cuales se hizo énfasis en el diálogo, la interacción dialógica y la comunión de proyectos de mundo que conduzcan a la construcción del conocimiento con compromiso social.

Palabras clave: Procesos Educativos. Esperanza. Metodología de investigación. Diálogo.

\footnotetext{
${ }^{1}$ Doutor em Educação pela UFSCar. Técnico de Laboratório Audiovisual do Departamento de Artes e Comunicação da UFSCar. E-mail: djalmajr@ ufscar.br. ORCID: http://orcid.org/0000-0002-4918-4600.

${ }^{2}$ Professora Titular da UFSCar. Co-líder do Grupo de Pesquisa "Práticas Sociais e Processos Educativos". Email: dmwo@ufscar.br. ORCID: http://orcid.org/0000-0001-6362-8581.
} 


\section{A ESPERANÇA COMO FORÇA QUE MOBILIZA, QUE EXPRESSA ANSEIOS E QUE UNE PESSOAS EM TORNO DE UMA DADA PERSPECTIVA DE MUNDO...}

Em 2019 foi realizado o sexto Seminário de Pesquisas em Práticas Sociais e Processos Educativos, promovido pela Linha de Pesquisa Práticas Sociais e Processos Educativos do Programa de Pós-Graduação em Educação da Universidade Federal de São Carlos - UFSCar (SEMINÁRIO, 2019). Nesse seminário, a comissão organizadora convidou pesquisadores e pesquisadoras a contribuírem com o debate sobre o esperançar - verbo que atrela a esperança à ação e que concebe o mundo como espaço e tempo de construções coletivas. As reflexões constantes deste ensaio foram apresentadas numa primeira versão no contexto desse seminário.

O texto de apresentação do seminário colocava algumas questões orientadoras: "Como as pessoas com quem trabalhamos nas pesquisas constroem suas esperanças, que esperanças constroem" (?). "Como, ao pesquisar Práticas Sociais e Processos Educativos, podemos contribuir para visibilizar, valorizar, pensar, criticar, construir, semear o esperançar, para esperançarmos" $(?)^{3}$.

O ensaio, aqui apresentado, partirá destas questões orientadoras e será organizado de forma a estabelecer um diálogo com a tese de doutorado intitulada "Processos educativos vivenciados em experiências de comunicação popular na Mostra Audiovisual de Cambuquira-MG (MOSCA)" (RIBEIRO JUNIOR, 2016).

A fim de se estabelecer o recorte proposto: o de olhar criticamente para a tese e partindo das questões orientadoras que sustentaram a temática do esperançar, algumas informações iniciais serão trazidas com a intenção de situar o leitor e a leitora.

Para dar conta do objetivo deste ensaio, é importante contextualizar que a tese foi realizada entre 2012 e 2016 e que serão tecidas algumas informações e impressões acerca da cidade de Cambuquira-MG, bem como indicar que o texto que se segue está organizado com destaques para as falas de sujeitos da pesquisa que possibilitam vislumbrar as veias pulsantes do esperançar presente na própria vida vivida em um dado tempo e espaço.

Um primeiro momento será dedicado a visibilizar as falas dos sujeitos da pesquisa (referente à tese de RIBEIRO JUNIOR, 2016) e que contribuem para compreendermos as dimensões do esperançar, por meio da perspectiva das pessoas que colaboraram com a investigação.

Adiante, será dada ênfase na concepção de ciência e na metodologia de pesquisa que orientou a elaboração da tese de Ribeiro Junior (2016), destacando caminhos que identificam na atitude de pesquisar algumas dimensões do esperançar.

Por fim, é estabelecida uma relação entre a palavra diálogo, como categoria analítica e dimensão metodológica que constrói, fortalece e cuida do esperançar.

A tese de Ribeiro Junior (2016) se dedicou a pesquisar processos educativos que são vivenciados em experiências de comunicação popular na MOSCA. Foi evidenciado que a MOSCA compõe processos de comunicações populares, aproximando perspectivas críticas em relação à concentração dos meios de comunicação e fortalecendo lutas em favor da democratização da sociedade, a qual passa pelo processo de democratização dos meios de comunicação. Neste percurso, foi possível identificar nos resultados da tese que os dados analisados apontaram para categorias que indicam processos educativos que valorizam o diálogo, as trocas, a criticidade, a participação, a autonomia, o pertencimento, a identificação, o engajamento, a afirmação e a apropriação.

\footnotetext{
${ }^{3}$ Trechos extraídos da apresentação do sexto seminário de pesquisas em Práticas Sociais e Processos Educativos (SEMINÁRIO, 2019).
} 
Em termos metodológicos, a construção da tese foi pautada pelo diálogo entre uma comunidade de trabalho (Oliveira et al., 2014a) constituída entre o pesquisador acadêmico e os sujeitos da pesquisa, bem como por colegas do grupo de pesquisa "Práticas Sociais e Processos Educativos". Foi apontado, também, que o pesquisador acadêmico possuía e ainda possui relações próximas com a MOSCA, da qual é um dos idealizadores e organizadores.

Cambuquira ${ }^{4}$ é uma cidade situada no circuito das águas no sul de Minas Gerais. $\mathrm{Na}$ região central da cidade se destacam antigas e grandiosas construções de hotéis que nos remetem ao tempo em que Cambuquira era conhecida e frequentada não somente pelas suas águas, mas, sobretudo, pelo seu cassino nos anos de 1930-40. Também possui um Parque das Águas onde concentram algumas fontes de águas minerais reconhecidas pelos seus efeitos terapêuticos.

A população mais antiga ainda guarda na memória o passado que remonta a uma Cambuquira muito próspera e financeiramente rica, frutos da exploração do ramo dos cassinos. Nesta época, Cambuquira possuía equipamentos culturais como o cinema, por exemplo, além de praças e passeios públicos bem estruturados que atendiam a elite brasileira que para lá se deslocava atraída pelo cassino e pelas águas minerais.

Com a proibição dos cassinos no Brasil, Cambuquira começou a declinar financeiramente e os investimentos nos equipamentos culturais e nos demais espaços públicos foram cessando, até se extinguirem de vez com o passar dos anos. O cinema, por exemplo, deixou de existir.

De acordo com o Instituto Brasileiro de Geografia e Estatística (IBGE, 2020), estima-se que a população de Cambuquira chegue a 12.812 habitantes em 2020.

Ao caminhar pelas ruas de Cambuquira é possível sentir que a cidade foi bastante movimentada em um passado remoto. A rua principal da cidade é cheia de grandes construções, com pé direito alto e que outrora abrigaram hotéis, cassinos e cinemas. As tintas descascando nas paredes destes grandes casarões funcionam como marcadores de páginas de um livro antigo que ainda espera o desenrolar da história. Os paralelepípedos das ruas contribuem para alicerçar uma história passada que parece insistir em não fluir. Há a sensação de se estar em um lugar do passado. Cenário este que é logo quebrado pela agitação da cidade, pelos movimentos das pessoas, pelos sons dos carros. Pouco a pouco percebe-se que no livro antigo vão surgindo marcações contemporâneas de uma história em movimento. O encontro dos jovens nas noites de fim de semana, ilustrando a socialização por meio da música que invade o silêncio da cidade, situada na beira de um reminiscente pedaço de mata atlântica já nos coloca na contemporaneidade. Há um mosaico entre o urbano e o rural que integra, no mesmo espaço, os cavalos e as carroças e os carros e as motos. De repente é possível sentir que a arquitetura antiga, que marca a memória de uma cidade que foi economicamente próspera na época dos cassinos, é o cenário de uma vida dinâmica experienciada por pessoas nas mais diversas práticas sociais presentes em uma cidade contemporânea. É neste contexto que jovens de Cambuquira se aproximam da MOSCA e vice-versa. Uma aproximação originalmente marcada pela curiosidade de conhecer o outro e que vai se revelando como a possibilidade de com o outro compartilharmos projetos, perspectivas e expectativas (RIBEIRO JUNIOR, 2016, p. 115).

O destaque dado à caracterização da cidade de Cambuquira-MG nos ajuda a compreender como as pessoas, que co-laboraram com a pesquisa, constroem suas

\footnotetext{
${ }^{4}$ As informações referentes à cidade de Cambuquira-MG foram extraídas de Ribeiro Junior (2016).
} 
esperanças e que esperanças constroem, uma vez que os sujeitos da pesquisa guardavam uma relação de pertencimento junto à cidade de Cambuquira-MG.

Antes de trazer as falas das pessoas que colaboraram com a pesquisa cabem algumas ponderações no sentido de alertar que todas as falas que serão destacadas estão contextualizadas no corpo do relatório da tese. Isto implica em dizer que, ao trazer as falas das pessoas para este debate sobre o esperançar, há sempre o risco de descontextualização e de interpretações aligeiradas que podem não refletir intenções, sentimentos, preocupações originais. Contudo, correr este risco, de forma prudente e respeitosa, é também contribuir para que possamos re-construir conhecimentos.

Outra ponderação importante é a de situar a pesquisa que deu origem à tese em diálogo com referenciais da educação popular e da comunicação popular, contextualizando, assim, processos educativos e comunicativos vivenciados em um ambiente de mobilização cultural que a MOSCA vem proporcionando desde o ano de 2005, quando ocorreu sua primeira edição. Dessa maneira, as falas remetem a reflexões que partem desta ambientalização e que, agora, estão sendo analisadas com o objetivo de buscarmos um diálogo com o processo do esperançar.

As falas das pessoas idosas remontam uma relação entre dois períodos históricos distintos de Cambuquira e que relatamos anteriomente: um período marcado pela exploração do cassino e que movimentou financeiramente a cidade, permitindo investimentos em equipamentos culturais; e um período que se inicia com a proibição dos cassinos e que míngua os investimentos financeiros na cidade, culminando com o fechamento de vários equipamentos culturais. A seguir reproduzimos alguns trechos destas falas ${ }^{5}$ :

Era prazeroso ir ao cinema. Era prazeroso passear na Rua Direita. Cambuquira era prazer... E hoje... Segundo eu escuto: 'ah, já teve, já teve, a cidade do já teve' (Dona Nina).

Então você me perguntou: o que é que você acha da cultura em Cambuquira? Não existe, infelizmente não existe [...] Povo unido jamais será vencido! Em Cambuquira, a única união que eu já vi em Cambuquira é naquele açúcar que é vendido lá no...Porque aqui não existe união, ninguém se une pra coisa nenhuma (Seu Cid Ney) ${ }^{6}$.

$\mathrm{Na}$ ocasião em que a tese foi elaborada, foram atribuídas a estas falas características de desesperança e de provocação. Contudo, ao mirar para estas falas com a perspectiva de buscar dimensões do esperançar, é possível compreender que as falas traziam um diagnóstico firme e seguro de pessoas mais velhas cujas experiências e memórias indicavam caminhos para as mais jovens. Trocar experiências de vida e compartilhar memórias sugerem, assim, ações que fortalecem o esperançar, uma vez que diagnósticos são pontos de partidas para se traçarem estratégias para a construção de um mundo que se projeta, um mundo em movimento e que vá ao encontro do inédito-viável.

Inédito-viável é compreendido como conceito apresentado por Paulo Freire (2005) e que aponta para uma transformação da realidade possível de ser atingida, desde

\footnotetext{
${ }^{5}$ Os nomes das pessoas participantes da pesquisa são verdadeiros e foram aqui transcritos conforme o consentimento livre e esclarecido de cada uma delas.

${ }^{6}$ Os trechos em destaque podem ser conferidos em detalhe em Ribeiro Junior (2016, p. 156). As falas de Dona Nina e Seu Cid Ney também estão presentes no documentário Cine Elite, realizado em 2005 por meio de oficina de realização audiovisual ofertada na MOSCA, coordenada por Djalma Ribeiro Junior e com a participação de alguns jovens que, depois de dez anos, contribuíram com a pesquisa que deu origem à tese de doutorado que está sendo articulada neste ensaio. Ambos foram moradores de Cambuquira e vivenciaram a época dos cassinos na cidade.
} 
que construída de forma coletiva e colaborativa. Para tanto, há a necessidade de se estabelecer processos que permitam uma leitura crítica do mundo e dos processos históricos que condicionam situações-limites que oprimem e marginalizam. O inéditoviável surge, portanto, da interação entre reflexão e ação em um dado tempo e espaço.

Por parte das pessoas jovens é possível identificar como o processo histórico local influencia nas perspectivas de mundo e nas tomadas de decisões. Abaixo reproduzimos um trecho da fala de uma jovem que faz um diálogo com as falas das pessoas idosas.

\begin{abstract}
Minha geração, apesar de morrer de amores por Cambuquira, se constituiu com base no lema 'Cambuquira é a cidade do já teve', entretanto nos últimos tempos percebemos que não é bem assim, aliás, nunca foi. Mesmo que hoje em dia não circule rios de dinheiro na cidade como na época dos cassinos e dos aquáticos, temos nossa cultura viva, temos nossas preciosidades aquíferas, temos nossa história, nosso estilo de vida, claro que ainda não atingimos o cenário de cidade ideal com o devido respeito à nossas fontes, mata, bens naturais e reconhecimento dos nossos patrimônios imateriais que produzem valores cognitivos, históricos, afetivos, ambiental etc., mas eles estão aí demonstrando o que a cidade tem (Simone) ${ }^{7}$.
\end{abstract}

A fala da pessoa jovem parte de uma constatação evidenciada pelas pessoas idosas e que instiga a mobilização e a atitude de afirmar uma identidade que está em construção. A cidade do "já teve" é a mesma cidade do "tem" em um processo contínuo de re-construção. Os cassinos se foram, mas as pessoas continuam. Os cassinos se foram, mas não levaram a vida junto... A vida segue e cabe às pessoas seguirem vivendo e convivendo. Estar no mundo e com o mundo é uma atitude dinâmica de ser em um mundo que está sendo. Ou seja, um mundo que não é estático e que guarda potencialidades de transformações.

Podemos compreender que as pessoas que colaboraram com a pesquisa partem de diagnósticos sustentados pelas experiências de vidas e pelas memórias. Neste processo, há uma análise crítica e bastante complexa dos processos históricos vivenciados em um dado espaço e tempo. Por mais doloridos que sejam os diagnósticos, eles não podem ser encarados como clausuras e sim como obstáculos a serem vencidos. E que não serão vencidos de forma individual. O mundo a se projetar é tarefa coletiva.

Outro destaque é o de que o esperançar se constrói com pertencimento a um espaço e tempo físico e simbólico, particular e social. Há uma complementação entre os diálogos e as tensões que são geradas destas dualidades. A cidade do "já teve" para uns, é a cidade do "tem" para outros... E "uns" e "outros" convivem na mesma cidade, experienciando momentos de diálogos e momentos de tensões. O esperançar, assim, exige tomada de decisões, escolhas a serem feitas, estratégias a serem traçadas, construção de acordos e de parcerias...

Estas exigências elencadas também se fazem presentes no ato de pesquisar quando se parte de que o pesquisar é também uma atitude política, uma tomada de decisão que se constrói em diálogo com pessoas que compartilham perspectivas de mundo semelhantes; e em tensões com grupos de pessoas que possuem perspectivas de mundo contrárias ou antagônicas. Este é o ambiente da construção do conhecimento no universo acadêmico.

As pesquisas levadas a cabo na linha de pesquisa Práticas Sociais e Processos Educativos partem da compreensão de que as práticas sociais são permeadas de

\footnotetext{
${ }^{7}$ Os trechos em destaque podem ser conferidos em detalhe em Ribeiro Junior (2016, p. 149). Simone é uma jovem negra que participa da MOSCA e que foi cursar graduação em História. É militante na defesa da preservação do meio ambiente e dos direitos da população negra.
} 
processos educativos (Oliveira et al., 2014b). São pesquisas que buscam se situar nas perspectivas de pessoas, grupos de pessoas, comunidades que estão, de alguma maneira, marginalizadas diante dos diversos sistemas que regulam a sociedade. Tais pesquisas se pautam em metodologias dialógicas e buscam no convívio com as pessoas, que fazem parte do processo de pesquisar, a construção coletiva de significados e sentidos que contribuem para a construção de conhecimentos eticamente reponsáveis e compromissados com a transformação do mundo em um espaço e tempo cada vez mais justo e democrático.

Diante destas compreensões é que nos debruçamos sobre a segunda questão orientadora elaborada pela comissão organizadora do seminário e que pretende instigar o debate acerca de "Como, ao pesquisar Práticas Sociais e Processos Educativos, podemos contribuir para visibilizar, valorizar, pensar, criticar, construir, semear o esperançar, para esperançarmos" (SEMINÁRIO, 2019).

A fim de colaborar com este debate, lançaremos mão, mais uma vez, de um olhar sobre a concepção de ciência e sobre as dimensões metodológicas que orientaram a tese de Ribeiro Junior (2016) e buscaremos tecer reflexões acerca de possibilidades para visibilizarmos, valorizarmos, pensarmos, criticarmos, construirmos, semearmos o esperançar, para esperançarmos.

Visibilizarmos o esperançar é o reconhecimento de que a pesquisa em Práticas Sociais e Processos Educativos se dá no convívio dialógico entre pessoas que estão na academia, com determinados objetivos e pessoas que estão em outros espaços formativos, também com seus próprios objetivos. Estabelecer acordos entre as pessoas e seus objetivos contribui para a comunhão de projetos. Desde esta perspectiva dialógica é possível compartilhar projetos de mundo e colaborar com a construção de conhecimentos com compromisso social, atrelando, de acordo com o pesquisador brasileiro de Educação Popular, Carlos Rodrigues Brandão (1981, p. 12) “[...] o próprio projeto científico de pesquisa ao projeto político dos grupos populares cuja situação de classe, cultura ou história se quer conhecer porque se quer agir".

Valorizarmos o esperançar significa reconhecer que há diversas maneiras de acessar e construir conhecimentos. Há os conhecimentos populares, os conhecimentos científicos... Um não é melhor e nem pior que o outro. São diferentes. E valorizar estas diferenças contribui para colocar os diversos conhecimentos em diálogo para que seja possível o estabelecimento de estratégias e de caminhos que fortaleçam o próprio projeto de mundo compartilhado, do qual a pesquisa científica está integrada, ou seja, não é possível existir neutralidade em um processo de construção de conhecimentos, uma vez que o que move este processo é um projeto de mundo. O sociólogo colombiano Orlando Fals Borda (1981, p. 43-44) alerta que a ciência não é "[...] uma entidade com vida própria, capaz de reger o universo e determinar a forma e o contexto de nossa sociedade, tanto presente quanto futura". Brandão (1981, p. 10) também indica que "[...] nenhum conhecimento é neutro e nenhuma pesquisa serve teoricamente 'a todos' dentro de mundos sociais concretamente desiguais".

Pensarmos o esperançar nos indica uma reflexão coletiva. $\mathrm{O}$ pensar está enraizado em um dado tempo e espaço, bebe do processo histórico e da situação conjuntural e se dá na intersubjetividade. Por mais que o pensar seja expressado por uma pessoa, aquela que escreve o relatório de pesquisa, por exemplo, ele é fruto de uma rede tão longínqua e tão diversa de pensamentos que nos obriga, eticamente, a compreender esta rede e assumir uma responsabilidade com o seu processo de fruição e que muito pode colaborar com a construção de conhecimentos dialogados. O sociólogo aymara Simón Yampara Huarachi (2011), na tentativa de estabelecer uma convivência em harmonia entre o conhecimento andino e o conhecimento ocidental, sugere a 
seguinte equação: "Conocimiento ancestral milenario + conocimiento occidental centenario $=$ conocimiento profundo $\mathrm{y}$ renovado. ¿Por qué no podemos hacer esa ecuación?" (p. 16).

Criticarmos (n)o esperançar é estabelecer a crítica ao conceito de esperança forjado dentro de uma única perspectiva de mundo e que se arroga como universal. Ou seja, há de se estabelecer uma posição crítica em relação à ciência que se quer absoluta, universal, neutra e que, assim, legitima perspectivas e subjuga outras. O esperançar se quedaria sucumbido dentro de uma concepção absoluta, universal e neutra! O filósofo argentino-mexicano Enrique Dussel (2001) identifica três critérios epistemológicos de demarcação do que vai se constituindo ciência e cientificidade no decorrer da história: $1^{\circ}$ critério ("ciência" ou pseudo-ciência); $2^{\circ}$ critério (ciência da natureza ou ciência social); $3^{\circ}$ critério (ciências sociais "funcionais" ou "críticas"). Esta terceira demarcação é importante para compreendermos como a ciência funcional atua intimamente em função de preservar e aprimorar a normatividade dentro da totalidade vigente, ou seja, a exterioridade $^{8}$ não faz parte do seu projeto; já a ciência crítica orienta sua perspectiva desde a exterioridade e integra em seu projeto a alteridade ${ }^{9}$. As ciências não são separadas das dinâmicas da vida, ou seja, as ciências condicionam e estão condicionadas aos aspectos políticos, econômicos, sociais e culturais. Nenhum conhecimento pode arrogar a si mesmo a universalidade, a neutralidade e a detenção do saber absoluto, conforme nos alerta o sociólogo português Boaventura de Sousa Santos (2010, p. 58) "[...] uma vez que nenhuma forma singular de conhecimento pode responder por todas as intervenções possíveis no mundo, todas elas são, de diferentes maneiras, incompletas". Se a incompletude é reconhecida, tal reconhecimento pode gerar atitude de trabalho coletivo e cooperativo, de disposição para o diálogo A atitude de transferir para um dado tipo de conhecimento ares de absolutismo ou, de outro lado, negar a importância dos processos de construções de conhecimentos já nos mostrou, no decorrer da história da humanidade, que somente contribui para o fortalecimento de discursos que pregam políticas sectárias, economias exploratórias, grupos extremistas, culturas elitistas e que abrem terreno para a construção e manutenção de processos de opressão, de humilhação, de repressão e de extermínio de pessoas, de grupos de pessoas e de culturas que não fazem parte de um dado projeto de mundo hegemônico em curso.

Construirmos o esperançar nos remete à ideia de processo. Ou seja, estamos sendo em um mundo sendo e nele podemos agir... Esta é uma das caraterísticas da

\footnotetext{
${ }^{8}$ O conceito de exterioridade remete aos trabalhos de Enrique Dussel acerca da Filosofia da Libertação e está articulado com o conceito de totalidade. Em suma, há um projeto de mundo totalizado e excludente que gera vítimas que vivem na exterioridade deste projeto. Esta vítima é o outro coisificado, oprimido dentro da lógica da totalidade. Dussel vai propor a filosofia da libertação que reconhece este outro como Outro que possui também outras perspectivas de mundo e que, colocado em diálogo em comunidade crítica, é possível a construção de uma filosofia desde a exterioridade, permitindo pensar mais além de um mundo totalizado cerrado e centrado na perspectiva eurocêntrica. Neste contexto que ele sugere o método analéctico. "El método ana-léctico surge desde el Otro y avanza dialécticamente; hay una discontinuidad que surge de la libertad del Otro. Este método, tiene en cuenta la palabra del Otro como otro, implementa dialécticamente todas las mediaciones necesarias para responder a esa palabra, se compromete por la fe en la palabra histórica y da todos esos pasos esperando el día lejano en que pueda vivir con el Otro y pensar su palabra, es el método ana-léctico. Método de liberación, pedagógica analéctica de liberación" (DUSSEL, 1995, p. 235-236).

${ }^{9} \mathrm{O}$ conceito de alteridade também é abordado na perspectiva defendida por Enrique Dussel. A alteridade não é apenas o reconhecimento da vítima como tal, mas a responsabilidade ético-crítica com a vítima dentro do sistema vigente e da ação para que se negue a negatividade da vítima, assegurando-lhe a manifestação da vida digna (DUSSEL, 1998). É neste ponto que Dussel reconhece na pedagogia de Paulo Freire uma proposta ético-crítica, uma vez que ambos os autores trabalham com a perspectiva das vítimas (oprimidos) num processo contínuo de libertação praticado pelas vítimas (oprimidos) a partir da conscientização, processo que inclui práxis, destes sobre sua condição.
} 
própria Educação, área do conhecimento em que se dão as pesquisas em Práticas Sociais e Processos Educativos. A pesquisadora Petronilha Beatriz Gonçalves e Silva destacou que a:

[...] educação é um processo inesgotável, inacabado que opera na experiência, nas relações com os outros, no dia a dia, e se concretiza numa maneira de se engajar no mundo, de tomar posição frente à situação humana. Educação é formação de identidade no seio de uma cultura, é assimilação e reconstrução dessa cultura, é compreensão de outras culturas (SILVA, 1987, p. 11).

E, mais adiante, ressaltou que a:

[...] educação é o ato de construir o nosso modo próprio de ser, juntamente com quem convivemos, ao assumirmos com eles os destinos do nosso grupo, nossa classe social, nossa comunidade. É vivência que permite tomar consciência do mundo, das coisas, das pessoas, das relações que entre eles se estabelecem, e assim tomar consciência de si próprio (SILVA, 1987, p. 64).

Semearmos o esperançar é a responsabilidade e o compromisso para com um projeto de mundo que seja dialógico, respeitoso, democrático. Um projeto de mundo que se constrói de forma dialógica, participativa, democrática. Um projeto de mundo que se conjuga no plural, que vai sendo construído com diferentes conhecimentos, com diferentes perspectivas. Um projeto de mundo que acolhe, que inclui, que não está dado, mas que é preciso construí-lo de forma coletiva, participativa. Um projeto de mundo onde esperança é verbo, é ação...

Foi por estas veredas que o processo de pesquisa tentou caminhar. Ao buscar responder a questão de pesquisa "[...] que processos educativos permeiam um processo de comunicação popular experienciada na Mostra Audiovisual de Cambuquira-MG (?)" (RIBEIRO JUNIOR, 2016, p. 53) a tese apontou para categorias que indicam processos educativos que valorizam o diálogo, as trocas, a criticidade, a participação, a autonomia, o pertencimento, a identificação, o engajamento, a afirmação e a apropriação.

Tais categorias nos ajudam, também, a estabelecer uma rede entre as pesquisas em Práticas Sociais e Processos Educativos e a construção do esperançar. Não apenas a construção, mas também o cuidado que o esperançar exige. Poderíamos tecer uma trama com cada categoria elencada na tese e como ela se relaciona com o esperançar, porém este seria um trabalho para outro momento.

Para o objetivo deste ensaio, gostaríamos de destacar o diálogo como categoria e como dimensão metodológica que constrói, fortalece e cuida do esperançar. O diálogo é o processo que fundamenta e que une, coerentemente, nossa posição teórica, epistemológica com nossas práticas cotidianas, que inclui o exercício da pesquisa. Neste sentido, o diálogo é constituinte da própria vida que se vai vivendo de forma coletiva. Concordamos com o educador Paulo Freire (2005) quando aponta que "[...] se não amo o mundo, se não amo a vida, se não amo os seres humanos, não me é possível o diálogo" (p. 92). Da mesma maneira que "[...] não há diálogo se não há uma intensa fé nos seres humanos. Fé no seu poder de fazer e de refazer. De criar e de recriar" (FREIRE, 2005, p. 93). Assim, “[...] saber falar, saber ouvir, cuidar de si, cuidar do outro são atitudes que se fundam e se fundamentam no diálogo" (RIBEIRO JUNIOR, 2009, p.107). O diálogo, na pesquisa, foi vivenciado como fundamento e como imperativo ético e metodológico. Ouvir os sujeitos da pesquisa possibilitou problematizar o contexto em que se deu todo o processo de pesquisar... E, agora, vemos que contribuiu com o esperançar... 


\section{REFERÊNCIAS}

BRANDÃO, C. R. Pesquisar-Participar. In: BRANDÃO, C. R. Pesquisa participante. São Paulo: Brasiliense, 1981. p. 9-17.

DUSSEL, E. El programa científico de investigación de Karl Marx. Ciencia funcional y crítica. In: DUSSEL, E. Hacia una filosofía política crítica. Bilbao: Ed Desclée de Brouwer, 2001. p. 279-301.

DUSSEL, E. Ética de la liberación en la edad de la globalización y de la exclusión. Madrid: Editorial Trotta, 1998.

DUSSEL, E. Introducción a la filosofía de la liberación. Bogotá: Editorial Nueva América, 1995.

FALS BORDA, O. Aspectos teóricos da pesquisa participante. In: BRANDÃO, C. R. Pesquisa participante. São Paulo: Brasiliense, 1981. p. 42-62.

FREIRE, P. Pedagogia do oprimido. Rio de Janeiro: Paz e Terra, 2005.

IBGE. Cidades. Panorama: população estimada em 2020 - Cambuquira, Minas Gerais. Disponível em: https://cidades.ibge.gov.br/brasil/mg/cambuquira/panorama. Acesso em: 20 set. 2020.

OLIVEIRA, M. W.; RIBEIRO JUNIOR, D.; SILVA, D. V. C.; SOUSA, F. R.; VASCONCELOS, V. O. Pesquisando processos educativos em práticas sociais: reflexões e proposições teórico-metodológicas. In: OLIVEIRA, M. W.; SOUSA, F. R. Processos educativos em práticas sociais: pesquisas em educação. São Carlos: EdUFSCar, 2014a. p. 113-141.

OLIVEIRA, M. W.; SILVA, P. B. G.; GONÇALVES JUNIOR, L.; GARCIA MONTRONE, A. V.; JOLY, I. Z. L. Processos educativos em práticas sociais: reflexões teóricas e metodológicas sobre pesquisa educacional em espaços sociais. In: OLIVEIRA, M. W.; SOUSA, F. R. Processos educativos em práticas sociais: pesquisas em educação. São Carlos: EdUFSCar, 2014b. p. 29-46.

RIBEIRO JUNIOR, D. Processos educativos vivenciados em experiências de comunicação popular na Mostra Audiovisual de Cambuquira-MG (MOSCA). 2016. 230 p. Tese (Doutorado em Educação) - Centro de Educação e Ciências Humanas, Universidade Federal de São Carlos, São Carlos, 2016.

RIBEIRO JUNIOR, D. Criação audiovisual na convivência dialógica em um grupo de dança de rua como processo de educação humanizadora. 2009. 142 f. Dissertação (Mestrado em Educação) - Centro de Educação e Ciências Humanas, Universidade Federal de São Carlos, São Carlos, 2009.

SANTOS, B. S. Para além do pensamento abissal: das linhas globais a uma ecologia dos saberes. In: SANTOS, B. S.; MENESES, M. P. Epistemologias do Sul. São Paulo: Cortez, 2010. p. 31-83.

SEMINÁRIO DE PESQUISAS EM PRÁTICAS SOCIAIS E PROCESSOS EDUCATIVOS, 6., 2019, São Carlos. VI Seminário [...]. São Carlos: UFSCar, 2019.

SILVA, P. B. G. Educação e identidade dos negros trabalhadores rurais do limoeiro. 1987. 293 p. Tese (Doutorado em Educação) - Faculdade de Educação, Universidade Federal do Rio Grande do Sul, Porto Alegre, 1987.

YAMPARA HUARACHI, S. Cosmovivencia Andina. Vivir y convivir en armonía integral - Suma Qamaña. Bolivian Studies Journal/Revista de Estudios Bolivianos, v. 18, p. 1-22, 2011. Disponível em: http://bsj.pitt.edu/ojs/index.php/bsj/article/view/42/394. Acesso em: 20 set. 2020.

Recebido em: 21 set. 2020.

Aprovado em: 26 out. 2020.

Motricidades: Rev. SPQMH, v. 4, n. 3, seç. esp., p. 345-353, set.-dez. 2020 | ISSN 2594-6463 |

DOI: http://dx.doi.org/10.29181/2594-6463.2020.v4.n3.secesp.p345-353 